\title{
Inclusão no Trabalho: A Vivência de Pessoas com Deficiência Intelectual
}

\author{
Nara Liana Pereira-Silva* \& Adelaine Vianna Furtado \\ Universidade Federal de Juiz de Fora, Juiz de Fora, Brasil
}

\begin{abstract}
RESUMO
O trabalho constitui um dos principais contextos de desenvolvimento dos jovens/adultos com deficiência. O presente relato apresenta a experiência de pessoas com deficiência intelectual sobre sua inclusão no trabalho. Realizaram-se entrevistas com quatro aprendizes com diagnóstico de deficiência intelectual e experiência ocupacional no comércio. Os resultados apontam que o insucesso na inclusão destes jovens/adultos se deveu tanto pela falta de preparação profissional, questões pessoais e socioemocionais, como pela dificuldade das empresas em receber as pessoas com deficiência. $\mathrm{O}$ estreitamento do vínculo entre a instituição profissionalizante e as empresas é de suma importância para o sucesso da inclusão, dentre outros fatores.

Palavras-chave: inclusão no trabalho; deficiência intelectual; educação especial; profissionalização.
\end{abstract}

\section{ABSTRACT \\ Inclusion in Work: \\ The Experience of Persons with Intellectual Disabilities}

Work is an important context of development for young people/adults with disabilities. This report presents the experience of people with intellectual disabilities about their inclusion at work. Four interviews were conducted with apprentices with the diagnosis of intellectual disability that had occupational experience in the trade sector. The results show that the failure to include these young people/adults was caused either by lack of professional preparation, personal and socio-emotional issues, as well as the difficulty of companies to receive people with disabilities. Stronger links between vocational institutions and companies are critical to the success of inclusion, among other factors.

Keywords: inclusion in the work; intellectual disabilities; special education; professionalization.

A deficiência intelectual (DI) vem sendo caracterizada por limitações significativas tanto nofuncionamento intelectual como no comportamento adaptativo expresso em habilidades conceituais, sociais e práticas, originando antes dos 18 anos de idade (American Association on Intellectual and Developmental Disabilities, 2010). Assim, dentro de um contexto social, as pessoas com DI experimentam uma incompatibilidade entre as suas competências pessoais e as demandas ambientais. O que remete à importância de suporte e apoio, possibilitando o desenvolvimento de habilidades sociais, cognitivas e emocionais expressas no maior contato social e, consequentemente, mais rela- cionamentos interpessoais, maior participação na escola e/ou comunidade.

Legalmente, desde a Declaração Universal dos Direitos Humanos, de 1948, há referência à universalização dos direitos, independente de qualquer condição. No Brasil, a Constituição da República Federativa, promulgada em 1988, já considerava vários direitos às pessoas com deficiências, dentre eles o trabalho (Gugel, 2003). Nesta perspectiva, é importante mencionar também a Convenção sobre os Direitos das Pessoas com Deficiência, a qual foi ratificada pelo Brasil em 2008 e aprovada pela Organização das Nações Unidas (ONU) em 2007. Trata-se de um docu-

\footnotetext{
Endereço para correspondência: Nara Liana Pereira-Silva - naraliana.silva@ufjf.edu.br.
} 
mento abrangente e complexo, no qual os direitos das pessoas com deficiência são reafirmados em todos os âmbitos. No artigo 27 verifica-se a importância da promoção ao trabalho, inclusive daqueles que tiverem adquirido uma deficiência no emprego, adotando medidas apropriadas, incluídas na legislação.

A Lei de Cotas, como é conhecida a Lei $n^{\circ} 8.213$, de 1991, é também um documento que garante o acesso ao emprego às pessoas com deficiências no Brasil. Esta lei obriga as empresas, a partir de 100 funcionários, a preencherem uma parcela de seus cargos com pessoas com deficiências (Ministério do Trabalho e Emprego e Secretaria de Inspeção do Trabalho, 2007). Documentos como este se configuram em uma tentativa de garantir a inclusão das pessoas com deficiências no mercado de trabalho, por meio de uma política de inclusão e de dispositivos legais que a assegurem. Porém, apesar da existência dessa legislação, não há garantia de que, de fato, a inclusão da pessoa com deficiência no mercado de trabalho esteja ocorrendo (Araújo \& Schmidt, 2006). Ressaltam-se como fatores para esta realidade, o descumprimento dos atributos legais, a carência de programas de formação profissional e a falta de acessibilidade nas empresas (Araújo \& Schmidt, 2006; Lobato, 2009; Masson, 2009; Tanaka \& Manzini, 2005).

Com relação à profissionalização, é importante ressaltar que a preparação para o trabalho ou profissionalização das pessoas com DI, parte do pressuposto de que o trabalho é uma das principais vias de inclusão social, permitindo ao indivíduo demonstrar suas potencialidades e competências, além do reconhecimento como cidadãos. Consequentemente, o trabalho exerce um efeito reabilitador na medida em que contribui para o aumento da autoestima e ajustamento pessoal do indivíduo (Mendes, Nunes, Ferreira \& Silveira, 2004).

O serviço de formação profissional para pessoas com DI, geralmente, vem sendo conduzido por instituições de atendimento especializado que, por meio de oficinas, visam estimular a capacidade produtiva, o desenvolvimento de competências e a aquisição de condutas sociais básicas voltadas para o trabalho (Governo do Distrito Federal, 2010). Porém, as oficinas, geralmente, acabam preparando os indivíduos para atividades que não fazem parte da demanda de oferta das empresas (Araújo, Escobal \& Ribeiro, 2006; Araújo, Escobal \& Goyos, 2008; Sassaki, 2003). Dessa forma, destaca-se a necessidade de uma parceria entre as empresas contratantes e as instituições de atendimento especializado que oferecem capacitação profissional. Tal vínculo objetiva garantir que as instituições promovam competências necessárias ao ingresso no mercado de trabalho competitivo, tais como as habilidades sociais, e que as empresas ofereçam programas de acompanhamento, garantindo uma estrutura física e social adequada no ambiente de trabalho (Araújo \& Schmidt, 2006; Tanaka \& Manzini, 2005).

A importância da satisfação pessoal com o emprego foi demonstrada pelos resultados do estudo de Jahoda et al. (2009), em que 35 pessoas com DI, na Escócia, percebiam a continuação de alguns benefícios, tais como o senso de propósito para vida, autoconfiança, sentimento de autonomia financeira e o prazer de conhecer pessoas no local de trabalho. Porém, esses participantes relataram poucas oportunidades de relacionamento social que se estendiam, também, para fora do local de trabalho, além de uma ansiedade sobre sua competência para atender às expectativas dos empregadores. Esse dado demonstra a necessidade de estreitamento das relações entre as empresas e as instituições profissionalizantes.

Os resultados do estudo de Meletti (1997) apontam também nessa direção, isto é, de que o trabalho é um contexto que pode promover a inclusão social, bem como, o desenvolvimento de habilidades e competências das pessoas com deficiências. Participaram do estudo seis integrantes de uma Oficina Abrigada de uma instituição de atendimento especializado no interior do estado de São Paulo. Para os participantes que não tinham experiência no mercado de trabalho competitivo, a profissionalização significava uma via de inserção nas relações de produção e consumo, uma continuidade do atendimento educacional, uma alternativa ao ócio, a aquisição de boa conduta e a forma de reconhecimento pessoal e profissional. Para os participantes com experiência no mercado de trabalho competitivo, a profissionalização era considerada uma alternativa ao ócio, ao desemprego e a estigmatização, uma continuidade de atendimento educacional e a aquisição de boa conduta.

Ressalta-se, portanto, a importância de investigar os aspectos emocionais, sociais e psicológicos que se configuram como características pessoais importantes para as pessoas em inclusão no mercado de trabalho, especialmente aquelas com DI. Tomasini (1996) e Masson (2009) evidenciam que não é frequente as pessoas com DI serem participantes dos estudos, sen- 
do suas reações, na maioria das vezes, entendidas como parte de um quadro de 'anormalidade', limitando a possibilidade de identificar os comportamentos que superam os obstáculos impostos, além dos benefícios advindos da formação profissional e inserção no trabalho. Assim, diante da escassez de dados na literatura (Pereira, Del Prette \& Del Prette, 2008), essa experiência profissional possibilitou dar oportunidade para as pessoas com DI falarem sobre si próprias e seu processo de inclusão no trabalho. Considera-se que, investigar e descrever sobre como as pessoas com DI percebem o seu processo de inclusão, pode ser um caminho promissor para subsidiar o planejamento de atividades na preparação do jovem com DI para o trabalho.

Diante da importância em obter dados, a partir dos relatos dos jovens e adultos com DI, este trabalho tem o objetivo de descrever a experiência de pessoas com deficiência intelectual relativa ao seu processo de inclusão no mercado de trabalho, focalizando a satis- fação/insatisfação, sentimentos e reações. Tais dados foram coletados durante estágio profissionalizante no Setor de Psicologia de uma instituição de atendimento especializado da cidade de Brasília, Distrito Federal.

\section{DESCRIÇÃO DA EXPERIÊNCIA PROFISSIONAL}

O presente estudo constitui-se em um relato de experiência, derivado da prática de estágio profissionalizante em Psicologia. Quatro jovens/adultos diagnosticados com DI, membros de uma instituição de atendimento especializado foram os participantes deste trabalho, sendo designados como P1, P2, P3 e P4. Todos, na ocasião da coleta de dados, moravam em regiões administrativas (cidades satélites) de Brasília e tiveram experiência de trabalho no ramo do comércio e haviam retornado à instituição de atendimento especializado, pois tinham sido demitidos ou pediram demissão. A Tabela 1 apresenta a caracterização dos participantes. Ressalta-se que todos tinham o Ensino Fundamental incompleto.

Tabela 1

Caracterização dos Participantes, Segundo o Sexo, Idade, Profissão, Salário e Horas Diárias de Trabalho

\begin{tabular}{llllll}
\hline Participantes & Sexo & Idade & Profissão exercida & $\begin{array}{l}\text { Salário recebido (em } \\
\text { salários mínimos) }\end{array}$ & $\begin{array}{l}\text { Horas diárias de } \\
\text { trabalho }\end{array}$ \\
\hline P1 & Feminino & 25 & Empacotadora & 1 salário & 8 \\
P2 & Feminino & 19 & Empacotadora & 1 salário & 6 \\
P3 & Masculino & 28 & Sem especificação & 1 salário e meio & 6 \\
P4 & Feminino & 32 & Auxiliar de cozinha & Menos de 1 salário & 8 \\
\hline
\end{tabular}

Para a realização das entrevistas foi utilizado um roteiro semiestruturado, cujas questões tinham a finalidade de coletar dados a respeito do processo de inclusão dos participantes no mercado de trabalho, os sentimentos e as reações decorrentes do insucesso na inclusão. Este roteiro foi adaptado do estudo de Masson (2009), de acordo com as necessidades do presente estudo. A entrevista foi realizada com cada um dos jovens separadamente, na própria instituição de atendimento especializado de acordo com a disponibilidade dos entrevistados, com duração média de quarenta e cinco minutos. Todos os participantes assinaram um Termo de Consentimento Livre e Esclarecido e suas famílias foram informadas sobre este trabalho autorizando-o. As entrevistas foram transcritas e, posteriormente, com base nos relatos verbais, foram construídas categorias que agrupassem os temas e assuntos recorrentes, procedendo-se à técnica usual de análise de conteúdo (Bardin, 1977). As categorias elaboradas para os temas identificados em cada questão da entrevista não são mutuamente exclusivas, isto é, uma pessoa pode ter relatado mais de uma categoria.

\section{O QUE AS ENTREVISTAS MOSTRARAM?}

Os resultados são descritos com base nas seguintes categorias de análise: (1) Utilização do salário recebido; (2) Características do local de trabalho; (3) Sentimentos em relação ao trabalho; (4) Participação da família no processo de inclusão; (5) Motivos da demissão; (6) Expectativas quanto ao futuro.

Em relação à utilização do salário recebido, isto é, sobre o que faziam/compravam com o dinheiro, os relatos indicaram: (a) comprar bens pessoais, tais co- 
mo, roupas e calçados $(n=1)$; (b) comprar bens pessoais e ajudar nas despesas domésticas $(\mathrm{n}=2)$; (c) colocar no banco $(\mathrm{n}=1)$. Em relação à interferência na utilização do dinheiro, a maioria relatou que não havia interferência $(n=3)$ de familiares, apenas, uma pessoa relatou haver interferência de membros da família. Alguns relatos:

Eu ganhava o salário mínimo. Eu comprei calça legging, calcinha... minha mãe saía comigo para ajudar escolher,... essas coisas de mulher,... arrumava o cabelo. Ninguém interferia no meu dinheiro, a minha mãe ficava com o meu cartão, porque ficava com medo de eu ser assaltada. $(\mathrm{P} 1)$

Um salário. Comprava roupa, ajudava em casa. Ninguém interferia. $(\mathrm{P} 2)$

Menos que o salário mínimo. Comprava nada, eles avisavam que o dinheiro estava lá e eu deixava lá. Ninguém interferia, mas minha mãe me achava pão dura. Quando quero dinheiro meu pai me dá. (P4)

Quanto às características do local de trabalho, os participantes relataram: (a) satisfação $(n=2)$, (b) insatisfação $(n=2)$ e (c) dificuldades. Em relação à satisfação, os participantes disseram que gostavam muito dos colegas de trabalho. Já, em relação à insatisfação foram apontados dois motivos: (a) falta de amizades no trabalho $(n=1)$; e (b) fatores emocionais $(n=1)$.

No tocante à existência de dificuldades no local de trabalho, os relatos indicaram: (a) falta de habilidade da pessoa ( $\mathrm{n}=3)$, tais como, bater cartão de ponto, memorizar recados e (b) barreiras atitudinais $(n=1)$, as quais se referem àquelas expressões que denotam atitudes discriminatórias advindas das noções preconceituosas, estigmatizantes e estereotipadas sobre as pessoas com deficiências. No presente caso, este tipo de ação impediu que o empregado incluído realizasse tarefas que desejava, por não acreditarem em sua capacidade.

Bater o cartão, ninguém me ensinou direito, eles têm que saber que a gente tem dificuldade, aí uns dos meus chefes que estava ali perto me explicou e disse pra próxima vez eu prestar atenção. Algumas pessoas ajudavam, mas nem todos os colegas eram prestativos. (P1)

Dar recado... memorizar... esquecia de dar recados, até hoje tenho que anotar senão eu esqueço. (P2)

Não levava compras nas casas, nunca levava, porque eles falavam que eu não sabia. (P3)
No que tange aos sentimentos em relação ao trabalho ou cargo exercido foram realizadas as seguintes perguntas: "Você gostava de seu trabalho? Do que mais gostava? Do que menos gostava?". Seguem respostas às primeiras questões:

Sim, demais da conta,... gostava de ajudar os colegas a empacotar, falar o que está certo ou não. Eu gostava quando estava empacotando. (P3)

No começo eu gostava, depois não, por causa das amizades, as meninas ficavam de piadinhas e implicâncias uma com as outras. Eu gostava mais de trabalhar no caixa exclusivo, porque era mais calmo. (P1)

Em relação ao que menos gostavam no trabalho, foram identificadas categorias que remetem às atividades específicas das funções que exerciam: (a) repor prateleiras; (b) limpar cômodos; (c) exercer funções específicas da cozinha. Seguem os relatos:

Preencher as prateleiras, quando o carrinho estava cheio, ficava pesado demais. (P3)

Não gostava de ficar na cozinha, não gostava de limpar o chão e banheiro. (P4)

Quanto ao apoio recebido da família, os relatos indicam: (a) apoio de todos os membros $(n=3)$ e (b) apoio de alguns membros $(n=1)$. Seguem-se os relatos:

Todos tiveram orgulho de mim, principalmente minha irmã R., ela disse que eu vou conseguir chegar lá. (P1)

Meu pai sim, minha mãe não. (P4)

Dos quatro participantes deste trabalho, um pediu demissão, dois foram demitidos e um participante não quis falar sobre esse tema. Foram identificados diferentes motivos para a demissão: (a) familiares, (b) dificuldades de interação social, (c) inabilidade no exercício do cargo, (d) furto. Relatos:

Eu pedi demissão, foi por motivo de família e também por que não tinha mais amigas. (P1)

Eles me demitiram por furto, mas eu me arrependi muito... tão feio o que eu fiz, peguei dinheiro do caixa. (P3)

Em relação às expectativas de futuro e o que desejavam fazer, os relatos indicaram: (a) desejo de trabalhar fora (n=3); (b) desejo em continuar na instituição de atendimento especializado $(n=1)$. Em relação àque- 
les relatos positivos ao ingresso em um novo emprego, as expectativas mencionadas foram: (a) exercer novo cargo no mesmo ramo $(\mathrm{n}=1)$; (b) necessidade de especialização, por meio de cursos $(\mathrm{n}=1)$; (c) expectativas inespecíficas $(n=1)$. Os relatos foram:

Quero voltar a trabalhar, queria trabalhar em supermercado de novo, não para a limpeza, se for eu não vou aceitar, só quero se for para empacotar ou ser ajudante de caixa. $(\mathrm{P} 3)$

Estou fazendo curso de informática, curso de beleza, cabelo... quero voltar a trabalhar fora, mas sou aposentada. (P2)

Não quero mais trabalhar fora, quero ficar aqui (na instituição), gosto daqui. (P1)

\section{DISCUSSÃO}

A análise das entrevistas mostrou que a família, está envolvida, de alguma forma, na inclusão de seu membro com DI. A importância da família para as pessoas com DI, em processo de inclusão no trabalho, ainda parece ser um assunto não muito investigado, mas pode ser compreendida como um dos fatores essenciais para que ocorra a empregabilidade da pessoa com deficiência (Sassaki, 2003). A família pode se constituir em uma barreira à empregabilidade na medida em que não adota ações positivas e satisfatórias em relação à pessoa com DI.

As questões referentes ao contentamento/descontentamento e o que gostavam/não gostavam no local de trabalho deixam clara a importância de haver um estreitamento entre instituição profissionalizante e empresa contratante. Apesar de dois participantes demonstrarem contentamento constante com o local de trabalho, dois deles manifestaram o contentamento apenas no início, o que pode indicar que o ambiente de trabalho não era muito atrativo. Esse dado pode ser discutido considerando a escassez de programas de profissionalização com foco no desenvolvimento de habilidades sociais e emocionais, conforme referiram Tanaka e Manzini (2005), como também pela falta de incentivo das empresas à acessibilidade social. É importante enfatizar que, conforme destacado por Araujo e Schmidt (2006), as empresas precisam garantir melhores condições sociais no ambiente de trabalho, principalmente através de uma sensibilização no seu quadro de funcionários, para que possam considerar e respeitar as diferenças estabelecendo, assim, uma cultura inclusiva na empresa. Isto é, as empresas precisam melhor se preparar também para receber as pessoas com deficiência em inclusão.

Como apontado na literatura apesar da existência de uma legislação que favoreça a inclusão das pessoas com deficiências no trabalho, este tipo de ação não garante a permanência dessas pessoas no emprego (Gugel, 2003; Sassaki, 2003), como foi o caso dos participantes deste trabalho. Na presente investigação, em relação à demissão, evidenciaram-se causas pessoais, sociais e de falta de preparação profissional. Aliado a esse dado, identificou-se que os jovens do presente trabalho, não gostavam, em síntese, das atividades que exerciam o que aponta para o fato de nem sempre se considerar os gostos e satisfação com o cargo, conforme demonstrado por Jahoda et al. (2009).

Apesar da inconveniência representada pela demissão, foi constatado que os participantes tinham expectativas de retornar ao emprego. Isso demonstra que os desligamentos, no geral, não acarretaram implicações danosas aos entrevistados. Somente uma pessoa relatou não ter desejo em retornar ao trabalho, preferindo continuar na instituição especial, o que pode ter sido motivado pela sensação de proteção e conforto que a instituição pode causar (Januzzi, 1992).

Apesar das limitações deste estudo, especialmente no que se refere ao número de participantes, as reflexões alcançadas nos remetem às questões que a literatura já vem apontando sobre a inclusão no trabalho para a pessoa com DI, tais como a falta de preparação profissional dessas pessoas e a escassez de acessibilidade social e cultura inclusiva nas empresas contratantes (Lobato, 2009; Masson, 2009; Tanaka \& Manzini, 2005).

Os dados encontrados neste relato demonstram a necessidade de os serviços profissionalizantes focalizarem o desenvolvimento de habilidades sociais, proporcionando apoio psicológico e emocional aos aprendizes. Por outro lado, as empresas empregadoras devem estar dispostas a investir em melhores condições físicas e sociais, estabelecendo uma cultura inclusiva que garanta acessibilidade social no ambiente de trabalho. Família e sociedade são fundamentais parceiras nesse processo, contribuindo para a minimização/extinção de barreiras que impedem a inclusão das pessoas com deficiências em nosso país. 


\section{REFERÊNCIAS}

American Association on Intellectual and Developmental Disabilities - AAIDD. (2010).

Intellectual disability: Definition, classification, and systems of supports. Retirado de http://www.aaidd.org/IntellectualDisabi lityBook/content_2678.cfm

Araújo, E. A. C., Escobal, G., \& Ribeiro, D. M. (2006). Planejamento e organização de serviços para a formação de pessoas com deficiência mental para o trabalho. In C. Goyos \& E. Araújo (Eds.), Inclusão social: Formação do deficiente mental para o trabalho (pp. 143-166). São Carlos, SP: RiMa.

Araújo, E.A.C., Escobal, G., \& Goyos, C. (2008). Suporte comunitário para o trabalho do adulto com deficiência mental: Revisão de um processo. In M. A. Almeida, E. G. Mendes \& M. C. P. I. Hayashi (Eds.), Temas em educação especial: Deficiências sensoriais e deficiência mental (pp. 338-345). Brasília: Capes - PROESP.

Araujo, J. P., \& Schmidt, A. (2006). A inclusão de pessoas com necessidades especiais no trabalho: A visão de empresas e de instituições educacionais especiais na cidade de Curitiba. $R e$ vista Brasileira de Educação Especial, 12, 241-254.

Bardin, L. (1977). Análise de conteúdo (L. A. Reto \& A. Pinheiro, Trans.). Lisboa: Edições 70.

Governo do Distrito Federal. Secretaria de Estado de Educação. Subsecretaria de Gestão Pedagógica e Inclusão Educacional. Diretoria de Execução de Políticas e Planos Educacionais. Gerência de Educação Especial. (2010). Orientação pedagógica: Educação especial. Brasília: Governo do Distrito Federal.

Gugel, M. A. (2003). Trabalho para pessoas portadoras de deficiência, instrumento de pleno exercício da cidadania. In Associacão de Pais e Amigos dos Excepcionais - APAE (Eds.), Trabalho e deficiência mental: Perspectivas atuais (pp. 17-34). Brasília: Dupligráfica.

Jahoda, A., Banks, P., Dagnan, D., Kemp, J., Kerr, W., \& Williams, V. (2009). Starting a new job: The social and emotional experience of people with intellectual disabilities. Journal of Applied Research in Intellectual Disabilities, 22, 421-425.
Januzzi, G. S. M. (1992). Oficina abrigada e a "integração" do "deficiente mental". Revista Brasileira de Educação Especial, $1,51-65$.

Lobato, B. C. (2009). Pessoas com deficiência no mercado de trabalho: Implicações da lei de cotas (Dissertação de mestrado). Universidade Federal de São Carlos.

Masson, M. J. B. (2009). Educação e trabalho: A constituição do trabalhador deficiente intelectual (Dissertação de mestrado). Universidade Metodista de Piracicaba.

Meletti, S. M. F. (1997). O significado do processo de profissionalização para o indivíduo com deficiência mental (Dissertação de mestrado). Universidade Federal de São Carlos.

Mendes, E. G., Nunes, L. R. O. P., Ferreira, J. R., \& Silveira, L. C. (2004). Estado da arte das pesquisas sobre profissionalização do portador de deficiência. Temas em Psicologia, 12, 105-118.

Ministério do Trabalho e Emprego e Secretaria de Inspeção do Trabalho. (2007). A inclusão de pessoas com deficiência no mercado de trabalho. Brasília: MTE/SIT.

Pereira, C. S., Del Prette, A., \& Del Prette, Z. A. P. (2008). Qual o significado do trabalho para as pessoas com e sem deficiência física?. Psico-USF, 13, 105-114.

Sassaki, R. K. (2003). Educação profissional e emprego de pessoas com deficiência mental pelo paradigma da inclusão. In Associação de Pais e Amigos dos Excepcionais - APAE (Ed.), Trabalho e deficiência mental: Perspectivas atuais (pp.111-132). Brasília: Dupligráfica.

Tanaka, E. D. O., \& Manzini, E. J. (2005). O que os empregadores pensam sobre o trabalho da pessoa com deficiência?. Revista Brasileira de Educação Especial, 11, 273-294.

Tomasini, M. E. A. (1996). Trabalho e deficiência mental: Uma questão a ser repensada. Revista Brasileira de Educação Especial, 2, 127-132.

Recebido: 06/09/2011 Última revisão: $17 / 07 / 2012$ Aceito: 03/08/2012 